\title{
High-rise construction in Russia as one of the objectives of improving the management mechanism for living standards of the population
}

\author{
Svetlana Sergeeva ${ }^{1, *}$ Lyudmila Komyshova $^{1}$, Natalia Nagibina $^{1}$ \\ ${ }^{1}$ Voronezh State Technical University, Moscow Avenue, 14, Voronezh, 394026, Russia
}

\begin{abstract}
The article is aimed at determining the significance of solving the problem of high-rise construction in Russia as one of the tasks of improving the mechanism of managing the living standards of the population. To determine the effectiveness of measures aimed at improving the quality of life management mechanism, the expert evaluation method is used. The paper presents the measures to improve the quality of life and consequently the migration attractiveness of the region. Despite a number of actual difficulties and lack of sufficient experience, there is an interest in the development of high-rise construction. The result of the analysis of the general demographic dynamics for the last fifteen years is shown. Migration is the most mobile tool for managing short-term demographic processes; therefore, great attention should be paid to this component. Moreover, it is necessary to take into account other consequences of migration.
\end{abstract}

\section{Introduction}

Under the current conditions of the actual economy in Russia, improving the quality of living standards of the population is one of the priority directions of social and economic policy. The living standard of the population being some kind of touchstone reflects the state of the economy. Many demographic indicators depend on it, for instance, the migration growth. People always choose a place where it is better to live. The economy is created by people and in for people's well-being. The connections are simply direct: sustainable economic development ensures employment of the population. The implementation of activities aimed at improving the living conditions of the population is one of the main groups of activities aimed at improving the standard of living and infrastructure security.

\section{Materials and Methods}

To determine the effectiveness of measures aimed at improving the mechanism for managing the quality of life of the population, the expert evaluation method is used.

\footnotetext{
*Corresponding author: sergeevas2@yandex.ru
} 
The expert evaluation method is based on the use of indirect and incomplete information, experience of experts and intuition. Persons involved as experts should be highly qualified specialists in the complying knowledge areas, have a great professional and practical experience.

\section{Results}

The expert is provided with the maximum possible amount of objective data related to the problem under analysis. The qualification of experts is tried to be improved through special tuition and training. In addition, the expert should be informed enough about the sources of the problem and ways of solving similar problems in the past. In order to ensure the independence of assessments, the possible interinfluence of experts is eliminated and the impact of extraneous factors is reduced. To determine the possibility of appearing of the solution outcomes, the method of estimate coordination is used, which consists in assessments given by experts independently from each other, and then in combining these assessments into one generalized [1]. The method of the analytical note is a variation of this method, which indicates the possibility of the solution outcome appearance and an explanation on this possibility. To coordinate the estimates, the weighted average probability value is calculated taking into account the validity of the expert.

Today, in the conditions of a "demographic winter", activities that attract migrants play a special role $[2,3]$. For this purpose, specific measures for the Voronezh region are determined (Table 1).

Table 1. Measures to improve the quality of life in terms of migration attractiveness

\begin{tabular}{|l|l|c|c|c|}
\hline № & \multicolumn{1}{|c|}{ Measure } & $\begin{array}{c}\text { Costs, } \\
\text { mln. rub }\end{array}$ & $\begin{array}{c}\text { Effect, } \\
\mathbf{\%}\end{array}$ & $\begin{array}{c}\text { Efficiency, } \\
\text { \% }\end{array}$ \\
\hline 3. & Migration attractiveness of the region. & 0,78 & 5,1 & 6,5 \\
\hline 3.1 & $\begin{array}{l}\text { Ensure the access of migrants to the social services: } \\
\text { health, social, educational and pension services. }\end{array}$ & 0,1 & 0,7 & 7 \\
\hline 3.2 & Simplify the registration system in the living quarters. & 0,05 & 0,9 & 18 \\
\hline 3.3 & Develop a network of personnel and recruiting agencies. & 0,05 & 0,1 & 2 \\
\hline 3.4 & $\begin{array}{l}\text { Develop a public service for the vocational guidance of } \\
\text { compatriots living abroad. }\end{array}$ & 0,05 & 0,3 & 6 \\
\hline 3.5 & $\begin{array}{l}\text { Direct compatriots living abroad on professional } \\
\text { trainings. }\end{array}$ & 0,1 & 0,8 & 8 \\
\hline 3.6 & $\begin{array}{l}\text { Improve the system of financial and material assistance } \\
\text { to compatriots living abroad. }\end{array}$ & 0,05 & 0,2 & 4 \\
\hline 3.7 & $\begin{array}{l}\text { Enlarge the membership of potential migrants for the } \\
\text { targeted program of resettlement assistance. }\end{array}$ & 0,1 & 0,1 & 1 \\
\hline 3.8 & $\begin{array}{l}\text { Improved information package and information materials } \\
\text { on the state program of resettlement. }\end{array}$ & 0,05 & 0,7 & 14 \\
\hline & $\begin{array}{l}\text { Improve regulatory and legal acts that consolidate the } \\
\text { rights and obligations of compatriots living abroad } \\
\text { amend the regulatory documents to shorten the deadline, } \\
\text { establish a special procedure for issuing permits for } \\
\text { temporary residence and residence permits for } \\
\text { compatriots living abroad). }\end{array}$ & 0,01 & 0,1 & 10 \\
\hline 3.10 & $\begin{array}{l}\text { Analysis of the implementation of regional resettlement } \\
\text { programs, evaluation of their effectiveness. }\end{array}$ & 0,01 & 0,2 & 20 \\
\hline 3.11 & Development of measures to address housing problems of & 0,01 & 0,1 & 10 \\
\hline
\end{tabular}




\begin{tabular}{|l|l|c|c|c|}
\hline & compatriots living abroad. & & & \\
\hline 3.12 & $\begin{array}{l}\text { Improvement of the system of state support for } \\
\text { compatriots living abroad. }\end{array}$ & 0,2 & 0,9 & 4,5 \\
\hline
\end{tabular}

The diagram is used for clarity of understanding (Fig. 1).

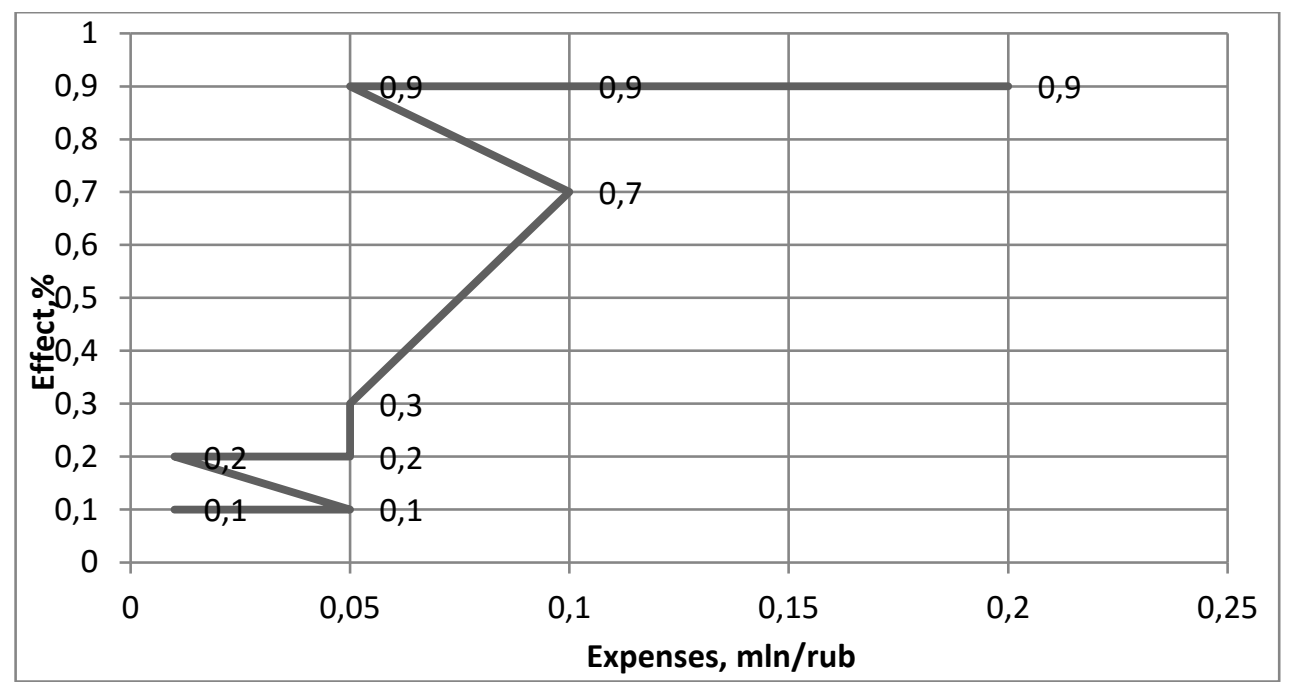

Fig. 1. Diagram of dependency between the effect (\%) and the expenses (million rubles) in terms of migration attractiveness of the region.

We use artificial neural networks to predict time series [4].

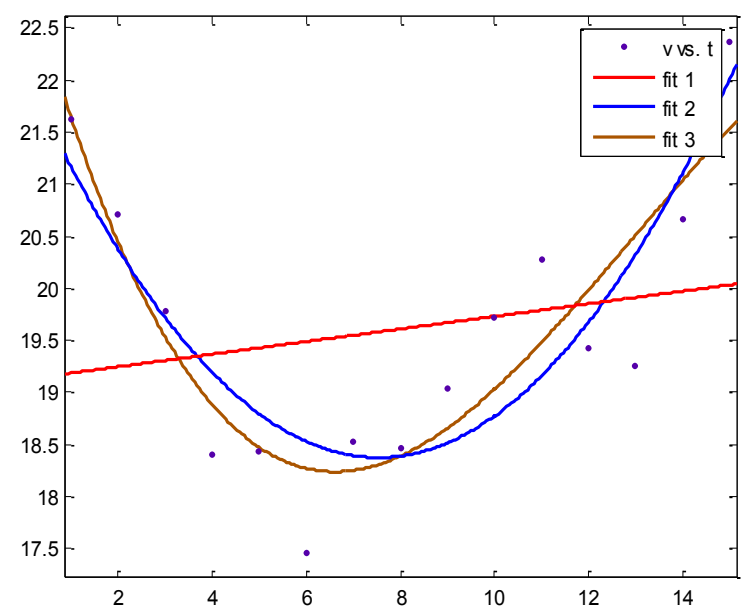

Fig. 2. Approximation of fertility data by linear -1 , quadratic -2 and cubic -3 polynomials 


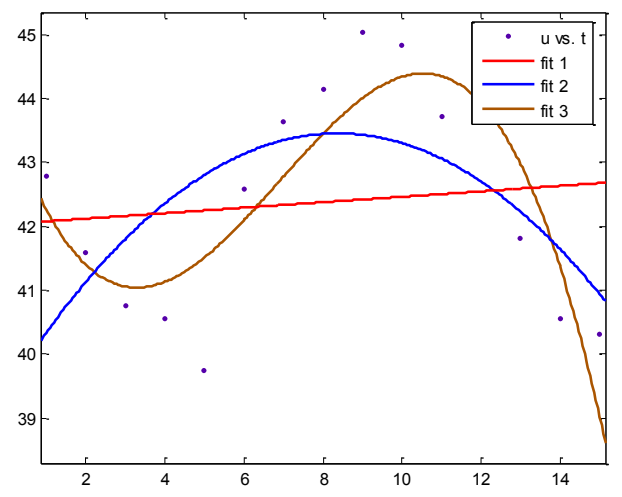

Fig. 3. Approximation of mortality data by linear - 1, quadratic - 2 and cubic - by 3 polynomials

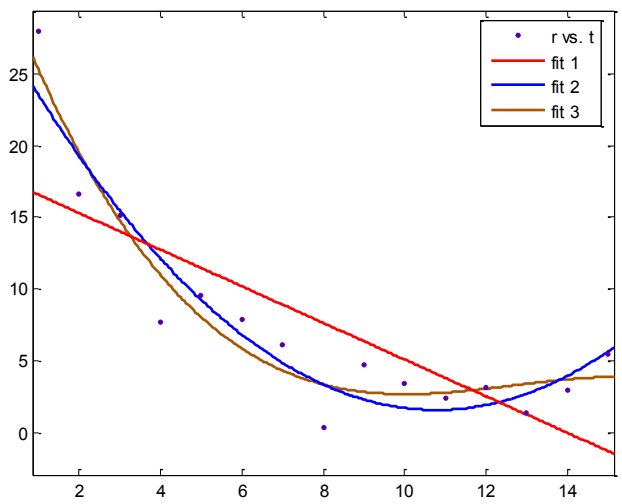

Fig. 4. Approximation of migration data by linear - 1, quadratic - 2 and cubic - by 3 polynomials

"From the analysis of figures 2-4 it follows that mortality and fertility will not change very much and in the first approximation they can be considered even constant. In addition, it can be assumed that there is an anticorrelation between them, which should be further verified. The most dynamic component was the migration one. It can be successfully approximated in the section of the parabolic curve under consideration"[5].

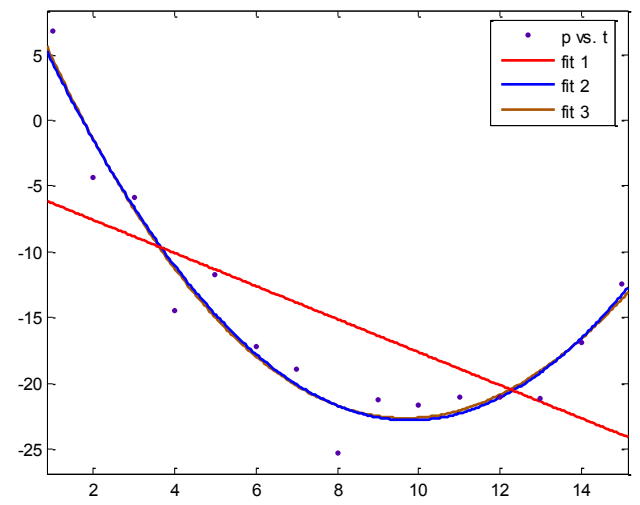

Fig. 5. Approximation of the general demographic dynamics by linear - 1, quadratic - 2 and cubic -3 polynomials 
Figure 5 shows the result of an analysis of the overall demographic dynamics over the past fifteen years. The parabolic law is seen to reflect the dependence quite well. Estimating the accuracy of the approximation using the R-square criterion gives a value of 0.94 . It is worth mentioning that the quality of the approximation is determined by the closeness of the value to one, which means that the result obtained is good enough. In general, the integral population change curve has a simple parabolic shape, and we will simulate it in more detail a little later. It can be seen that migration is the most mobile tool for managing short-term demographic processes, so attention to this component should be quite large. Moreover, it is necessary to take into account other consequences of migration.

\section{Discussion}

"Perhaps the most important issue of modern housing construction along with the problem of increasing the volume of housing commissioning, is the question: "What should be built?". The development of market relations has led to an "explosion" in the housing construction area, which is typological although barely noticeable. Along with the usual large-panel housing construction, houses with different planning and constructive structures have appeared, the construction of single-family and low-rise buildings with high-density indices has become more active. The phenomenon of elite housing has been identified. New construction technologies are being introduced. So the sharper the question arises: "What of things that can be built is really need to be built?" [6]. Despite a number of objective difficulties and lack of sufficient experience, there is an interest in the development of highrise construction. High-rise buildings can have different purposes: hotels, offices, residential buildings. A high-rise building is most often multifunctional and besides the main premises contains parking lots, shops, offices, cinemas, etc. The implementation of high-rise construction is dictated by the real shortage of construction sites in the largest cities, partly by the deficit of office and hotel areas, which are rational to place in high-rise buildings, as international experience shows. In the short term, particularly this direction in the development of skyscrapers should be expected, with the refusal to place residential premises there. Finally, the people's psychological attraction to the victory over the height should be always considered. The most valuable experience for domestic practice is the experience of city planners in European capitals, first including:

- consistent concentration of forces on a very limited number of sites.

- subordination of the design of the building to the principles of integrated urbanism with the complexity of development and the deployment of transport networks at several levels;

- ensuring the complexity of the development due to the combination of objects of different functional purposes in buildings, the space-planning solution, which most harmoniously meets their functions, which first of all means the combination of various buildings for various purposes in complex development;

- combination of a wide range of buildings in housing development (offices, dwellings, hotels, public services, educational institutions, trade, entertainment and sports) in order to create a wide range of workplaces for the majority of the population of the complex and its full service;

In modern conditions, the study of demographic processes in regulating and planning the socio-economic development of the regions is becoming increasingly important. The stage of the demographic crisis has finished: the "demographic dividend" has been exhausted, so Russia is expected to continue the natural decline of the population at the new stage of development, but now it will pass within a period of unfavorable changes in age composition. 
Without taking into account the demographic factors, it is impossible to implement in practice and scientifically justify medium-term and long-term regional economic development programs. Being the main productive force of society, a person is the creator of social wealth; therefore, the number of people and, especially, the working population with its qualifications is a factor that influences the opportunities for further social and economic development.

Investigations and works of many economists were dedicated to the issues of raising the standard of living. The works of K. Marx played a significant role in the development of their methodological foundations. A significant contribution to the study of the standard of living of the population, taking into account the peculiarities of the Russian economy, was made by the following domestic economists: Gerasimov, V.V. Drobysheva, V.V. Zharikov, O.A. Zhuravleva, M.A. Kolomeitseva, S.I. Sergeeva.

It is worth mentioning the studies of the All-Russian Center for Living Standards, conducted under the leadership of VN. Bobkova. Definition of the quality of life according to V. N. Bobkov.: "The quality of life is a variety of abilities and satisfied needs of the individual, social groups and society as a whole, predetermining their development and well-being" [7].

The above-mentioned and other scientists made a significant contribution to the study of the standard of living of the population. "This refers to the definition of this concept, indicators of measurement, characterization of the state and the search for ways to grow in different countries. The standard of living is one of the most significant categories describing the social and economic state of society. The well-being of the population is the level of income, material and housing security, which is an important indicator of the quality of life of the population. Housing security is one of the main indicators of wellbeing "[8].

The aim of the study is to find solutions of the problems of life quality, using advantages of the high-rise construction.

As methods for predicting demographic processes in the Voronezh region, the method of expert assessments, the method of statistical analysis, the method of mathematical modeling, neural networks are used.

The main priority in the design and construction of high-rise buildings is to ensure their strength and stability, as well as rigidity, taking into account the impact of considerable wind forces.

This requires the search for new technical and technological solutions.

\section{Conclusion}

When forecasting the demographic indicators of the Voronezh region, it should be noted that in our version of the demographic burden, the negative component predominates, but the migration processes will enlarge the population. Providing the population with quality housing leads to improving the quality of life of the population.

In conclusion, a few words should be said about the economic side of the issue. The cost of high-rise buildings is much higher than of the objects of mass construction, and is determined not only by specific design solutions, but also life support systems and complex security requirements. When designing high-rise buildings, economically justified technical solutions surely should be made, but they should not reduce the reliability of the structure and make it a source of increased danger to people and the environment. Only under these conditions high-rise buildings will become a kind of visiting card of the state, speak for its economic well-being and achievements of scientific and technical progress in the construction industry [9]. 
The world practice of high-rise construction has revealed that uneven reduction in length under the load is one of the most difficult aspects for vertical bearing structures of reinforced concrete.

This requires the search for new technical and technological solutions.

\section{References}

1. P.P. Oleynik, T.K. Kuzmina, Technology and organization of construction industry, 2(3), 18-20 (2013)

2. A. Purnus, C.-N. Bodea, Engineering Procedia, 164, 98-105 (2016)

3. N. Grau. Social and Behavioral Sciences, 74, 10-20 (2013)

4. V. I. Popov, Scientific problems of design, construction and exploitation of bridges and tunnels, Moscow, 11-20 (2014)

5. I.G. Lukmanova, M.Y. Mishlanova, International Journal of Economics and Financial Issues, 5, 208-216 (2015)

6. V.N. Bobkov, vestnik vgu, 2, 26-36 (2009)

7. B.F. Bylov, Nauka (1966)

8. S.I Sergeeva, Voronezh, 116-119 (2010)

9. S.I. Sergeeva, L.N. Komyshova, Voronezh, 247-253 (2010) 